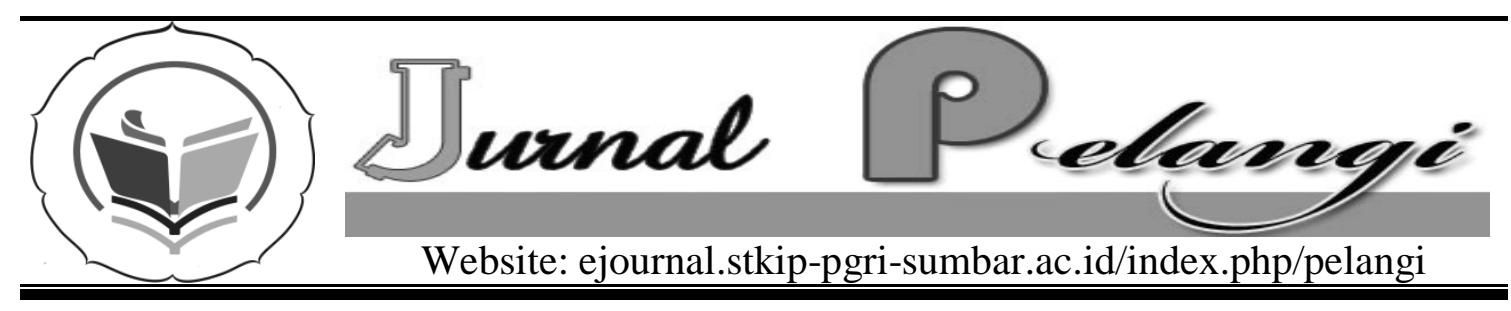

\title{
PENGGUNAAN MODEL PEMBELAJARAN KOOPERATIF TIPE STAD TERHADAP KEMAMPUAN KOMUNIKASI TEMATIK MAHASISWA PROGRAM STUDI PENDIDIKAN MATEMATIKA STKIP PGRI SUMBAR
}

\author{
Villia Anggraini
}

STKIP PGRI Sumatera Barat

INFO ARTIKEL

\section{Diterima:}

Direview:

Disetujui:

Kata Kunci:

communication ability, STAD, differential equations.

\section{Abstrak}

The cause of students' low achievement in mathematic in teaching learning process is because the teaching method is not varied. Thus, this research is aimed to find out: Are students' communication mathematic using cooperative learning- STAD better than those who use conventional strategy. The population was students of 2009A and 2009E of STKIP PGRI west Sumatera in 2010/2011 academic year who was taken simple differential equations and the sample was purposive sampling technique. The instrument was post test which was analyzed using U Mann-Whitney test. The data analysis shows that: Students who use cooperative learningSTAD have better competence on mathematic communication than those who use conventional strategy.

\section{PENDAHULUAN}

Persamaan Diferensial Biasa merupakan kelompok mata kuliah keahlian berkarya (MKB) pada Program Studi Pendidikan Matematika. Mata kuliah ini membahas jenis-jenis persamaan diferensial biasa dan penyelesaiannya, sistem persamaan diferensial dan penggunaannya dibidang geometri, fisika, kimia, kedokteran dan lainnya. Tujuan khusus mata kuliah persamaan diferensial biasa adalah agar mahasiswa mampu memahami konsep persamaan diferensial dan penyelesaiaannya.

Pada Mata kuliah Persamaan Diferensial Biasa (PDB) mahasiswa merasa kesulitan dalam membedakan jenis-jenis dan solusi umum dari persamaan diferensial. Ada tujuh jenisjenis persamaan diferensial (PD) dengan solusi yang berbeda- berbeda, seperti: PD variabel terpisah, PD homogen dan tak homogen, PD eksak dan non eksak, PD linier dan bernouli. Masing-masing PD mempunyai bentuk umum $\mathrm{M}(\mathrm{x}, \mathrm{y}) \mathrm{dx}+\mathrm{N}(\mathrm{x}, \mathrm{y}) \mathrm{dy}=0$. Dari 
bentuk umum tersebut mahasiswa harus mampu menyelesaikan solusinya. Hasil pengamatan peneliti selama mengampu mata kuliah Persamaan Diferensial Biasa, sebagaiam besar mahasiswa tidak bisa membedakan jenis- jenis PD, sehingga mahasiswa merasa kesulitan dalam menyelesaikan solusi PD tersebut. Seperti contoh soal yang diberikan, Selesaikan persamaan diferensial

$$
\frac{d y}{d x}=\frac{4 y}{x(y-3)} \text {. }
$$

Pada tahap penyelesaian, mahasiswa harus bisa mengetahui jenis persamaan Diferensial tersebut. Namun sebagian besar mahasiswa menyatakan bahwa bentuk persamaan diferensial tersebut adalah PD Homogen dengan derajat satu, sehingga mahasiswa menyelesaikan solusi umum dengan langkah-langkah PD Homogen. PD tersebut adalah PD Variabel Terpisah dengan penyelesaian sebagai berikut:

Penyelesaiannya :

$$
\begin{aligned}
& \frac{d y}{d x}=\frac{4 y}{x(y-3)} \\
& 4 y d x=x(y-3) d y \\
& 4 y d x-x(y-3) d y=0 \\
& \frac{4}{x} d x-\frac{(y-3)}{y} d y=0 \\
& 4 \ln x-(y-3 \ln y)+c=0 \\
& \ln x^{4}+\ln y^{3}+\ln c=y \\
& y=\ln \left(c x^{4} y^{3}\right)
\end{aligned}
$$

Hal di atas membuktikan bahwa mahasiswa kurang mampu menyajikan persoalan matematika dengan tahaptahap penyelesaiannya. Ini membuktikan bahwa kemampuan komunikasi mahasiswa yang kurang optimal.
Salah satu upaya yang harus dilakukan adalah bagaimana mahasiswa memiliki kecakapan dan kemahiran dalam matematika. Oleh karena itu, perlu diupayakan agar mahasiswa memiliki pemahaman konsep yang tinggi. Untuk mengatasi permasalahan tersebut digunakan model pembelajaran kooperatif tipe Student Teams Achievement Devision (STAD). Model pembelajaran kooperatif tipe STAD memungkinkan dosen memfasilitasi dan membimbing mahasiswa melakukan proses perkuliahan dalam kelompok kecil, meningkatkan interaksi yang efektif diantara anggota kelompok. Melalui model pembelajaran kooperatif tipe STAD, mahasiswa bersama-sama memikirkan, menemukan, menggunakan atau mengkontruksikan sendiri pengetahuan yang diperoleh dengan bimbingan dan dorongan dosen.

Berdasarkan kondisi-kondisi di atas maka tujuan penelitian ini adalah mengetahui apakah kemampuan komunikasi matematik mahasiswa yang mengikuti perkuliahan dengan model kooperatif tipe STAD lebih baik dari kemampuan komunikasi matematik mahasiswa yang mengikuti perkuliahan dengan konvensional.

\section{KAJIAN TEORI}

1. Model Pembelajaran Kooperatif Tipe STAD

Model pembelajaran kooperatif tipe STAD merupakan salah satu model pembelajaran yang cukup sederhana dan sangat efektif digunakan oleh para guru/dosen untuk memperbaiki aktifitas dan mutu perkuliahan di kelas. Pembelajaran kooperatif tipe STAD menempatkan mahasiswa belajar dalam kelompok heterogen, sehingga mahasiswa dapat berdiskusi secara aktif mencari dan memahami konsep-konsep materi perkuliahan. 
Slavin dalam Asma (2008:50) menjelaskan bahwa pada pembelajaran kooperatif tipe STAD mahasiswa ditempatkan dalam kelompok belajar yang beranggotakan 4 atau 5 orang mahasiswa yang merupakan campuran kemampuan akademik yang berbeda, sehingga dalam setiap kelompok terdapat mahasiswa yang pandai, sedang dan kurang. Kegiatan pembelajaran kooperatif tipe STAD terdiri dari enam tahap yaitu:

a. Penyajian Materi Pelajaran

1) Memberikan materi pelajaran sesuai dengan apa yang akan dipelajari mahasiswa dalam kelompok.

2) Pembelajaran kooperatif menekankan pada pembelajaran bermakna.

3) Mengecek pemahaman mahasiswa sebanyak mungkin.

4) Menyuruh mahasiswa menjawab pertanyaan-pertanyaan yang diberikan.

5) Mengambil mahasiswa secara acak untuk menjawab pertanyaan supaya mahasiswa selalu mempersiapkan diri sebanyak mungkin.

b. Kegiatan Kelompok

Pada kerja kelompok, dosen membagikan lembar kerja mahasiswa untuk didiskusikan kepada masingmasing kelompok. Masing-masing kelompok diberi pertanyaan. Pertanyaan disesuaikan dengan urutan tujuan pembelajaran yang hendak dicapai. Mahasiswa dalam menyelesaikan soal dapat mengerjakan secara berpasangan. Kemudian mereka saling mencocokkan jawaban dengan teman kelompok. Jika ada anggota yang belum memahami,

kelompok bertanggungjawab untuk menjelaskan sebelum meminta bantuan dosen. c. Evaluasi

Dosen menyelenggarakan tes untuk mengukur pengetahuan yang diperoleh mahasiswa. Mahasiswa mengerjakan tes secara individu dan tidak diperkenankan saling membantu.

d. Penghargaan Kelompok

1) Menghitung skor individu dan skor kelompok.

Tabel 3. Perhitungan skor perkembangan kelompok

\begin{tabular}{|l|c|}
\hline \multicolumn{1}{|c|}{ Skor tes akhir } & Nilai perkembangan \\
\hline Lebih dari 20 poin dibawah skor awal & 5 \\
20 hingga 1 poin dibawah skor awal & 10 \\
Skor awal hingga 20 poin diatas skor awal & 20 \\
Lebih dari 20 poin diatas skor awal & 30 \\
Nilai sempurna & 30 \\
\hline
\end{tabular}

2) Menghargai prestasi kelompok.

Tabel 4. Tingkat penghargaan kelompok

\begin{tabular}{|c|c|}
\hline Nilai Rata-rata kelompok & Penghargaan \\
\hline $5-14$ & Baik \\
$15-24$ & Hebat \\
$25-30$ & Super \\
\hline
\end{tabular}

e. Perhitungan ulang skor awal dan pengubahan kelompok

Setelah satu periode penilaian, dilakukan perhitungan ulang skor evaluasi sebagai skor awal mahasiswa yang baru. Selain itu juga dilakukan perubahan kelompok kooperatif yang berguna untuk memberi kesempatan pada mahasiswa bekerja dengan teman yang lain dan memelihara agar pembelajaran tetap segar. 


\section{Kemampuan Komunikasi Matematik}

Kata komunikasi seperti yang diungkapkan Liliweri (1997:3) berasal dari bahasa latin communicare, berarti berpartisipasi atau memberitahukan. Kata communis berarti milik bersama atau berlaku dimana-mana sehingga communis opinion.

Menurut Muhammad (2007: 17), ada lima komponen dasar komunikasi. Lima dasar tersebut, yaitu pengirim pesan (dosen), pesan (materi perkuliahan), saluran (proses/media yang digunakan), penerima pesan (mahasiswa), dan balikan (kemampuan mahasiswa menerima materi). Lebih lanjut Abizar (1988: 3) mengemukakan agar pesan/materi perkuliahan dapat diterima dengan baik maka antara sumber dan penerima pesan harus aktif melakukan pengkodean (encoding) dan pembukaan kode (decoding). Proses pengkodean yaitu penerjemahan ide ke dalam pesan yang cocok untuk disampaikan yang dilakukan oleh sumber. Proses pembukaan kode yaitu proses penerjemahan atau pembacaan arti dari suatu stimulus yang dilakukan oleh penerima pesan.

Dalam matematika komunikasi adalah suatu aktivitas penyampaian dan atau penerimaan gagasan-gagasan matematika dalam bahasa matematika. Hal ini sangat mungkin karena matematika itu sendiri adalah bahasa, sebagaimana yang diungkapkan oleh Suriasumantri dalam Fadjar (2004; 20) mengatakan bahwa matematika adalah bahasa yang melambangkan serangkaian makna dari pernyataan yang ingin kita sampaikan.

Menurut Romberg dan Chair dalam Sumarmo (2002:15), salah satu aspek berpikir tingkat tinggi dalam matematika adalah kemampuan komunikasi dalam matematika. Kemampuan tesebut yaitu menghubungkan benda nyata, gambar dan diagram ke dalam ide matematika; menjelaskan ide, situasi dan relasi matematika secara lisan atau tulisan dengan benda nyata, gambar, grafik dan aljabar; menyatakan peristiwa sehari-hari dalam bahasa simbol matematika; mendengarkan, berdiskusi dan menulis tentang matematika; mencoba dengan pemahaman suatu presentasi matematika tertulis; membuat konjektur, menyusun argumen, merumuskan definisi dan generalisasi; menjelaskan dan membuat pertanyaan tentang matematika yang telah dipelajari.

Indikator komunikasi matematika menurut John (2008:5) adalah sebagai berikut:

a. Mengatur dan menggabungkan pemikiran matematika melalui komunikasi

b. Mengkomunikasikan pemikiran matematika secara koheren dan jelas

c. Menganalisa dan menilai pemikiran dan strategi matematika orang lain

d. Menggunakan bahasa matematika untuk menyampaikan ide dengan tepat.

Berkaitan dengan komunikasi matematika, Rahman (2008:684) menyatakan kemampuan yang tergolong pada komunikasi matematika di antara lain adalah:

a. Menyatakan suatu situasi, gambar, diagram atau benda nyata ke dalam bahasa, simbol, idea, atau model matematika.

b. Menjelaskan idea, situasi, dan relasi matematika secara lisan dan tulisan.

c. Mendengarkan, berdiskusi dan menulis tentang matematika,

d. Membaca dan pemahaman suatu representasi matematika tertulis,

e. Membuat konjektur, menyusun argumen, merumuskan defenisi, dan generalisasi, 
f. Mengungkapkan kembali suatu uraian atau paragraf matematika dalam bahasa sendiri.

Jadi dalam penelitian ini dipakai indikator menyajikan ide matematika dalam bentuk aljabar dan model matematika, menggunakan struktur atau pola untuk menyajikan ide matematika.

\section{METODOLOGI PENELITIAN}

\section{A. Jenis Penelitian}

Penelitian ini merupakan penelitian eksperimen dengan rancangan penelitian yang digunakan adalah Posttest-Only Control Design. Penelitian ini dilakukan terhadap dua kelompok yaitu kelompok eksperimen ( kelas yang yang menggunakan model pembelajaran kooperatif tipe STAD) dan kelompok kontrol (kelas yang menggunakan pembelajaran model konvensional).

\section{B. Sampel}

Pengambilan sampel dilakukan secara Purposive. Kelas 2009 A dan 2009 E yang dipilih sebagai kelas sampel penelitian, karena kedua kelas merupakan kelas yang penulis ajar.

C. Prosedur penelitian

1. Tahap persiapan

a. Menentukan jadwal penelitian.

b. Mempersiapkan instrument pengumpulan data berupa lembar kerja mahasiswa, kuis dan tes pemahaman konsep matematik.

2. Tahap pelaksanaan
a. Pada kelas eksperimen kooperatif tipe STAD. dilakukan model pembelajaran
b. Pada kelas kontrol dilakukan pembelajaran konvensional.
c. Pembelajaran pada kelas kontrol dilakukan dengan pembelajaran biasa.

3. Tahap penilaian

Pada pertemuan terakhir dilakukan tes hasil belajar pada pemahaman konsep.

\section{Teknik Pengumpul Data}

Teknik pengumpulan data kuntitatif berupa tes kemampuan komunikasi matematik yang mengikuti perkuliahan dengan model kooperatif tipe STAD. Tes disusun sesuai dengan indikator kemampuan komunikasi.

\section{E. Teknik Analisis Data}

Analisis data kuantitatif dilakukan untuk menguji hipotesis yang telah dirumuskan. Untuk menentukan uji statistik yang digunakan, terlebih dahulu ditentukan normalitas data, dan homogenitas variansi. Langkah-langkah teknik analisis data kuantitatif adalah sebagai berikut:

1. Uji Persyaratan Analisis

a. Uji normalitas

Uji normalitas bertujuan untuk melihat apakah data sampel berdistribusi normal atau tidak. Uji normalitas yang digunakan adalah Liliefors, seperti yang dikemukakan Arikunto (1999).

1) Hasil belajar siswa $x 1, x 2 \ldots \ldots . . . x n$ dijadikan angka baku $\mathrm{z} 1$, z2. .zn

dengan menggunakan rumus :

$$
\begin{aligned}
& z_{i}=\frac{x_{i}-\bar{x}}{s} \\
& \text { Dimana: } \bar{x}=\text { rata-rata }
\end{aligned}
$$

$\mathrm{S}$ = simpangan baku 
2) Untuk setiap bilangan baku ini dengan menggunakan daftar distribusi normal baku, kemudian dihitung peluang. $\mathrm{F}(\mathrm{Zi})=\mathrm{P}(\mathrm{Z} \square \mathrm{Zi})$

3) Menghitung proporsi z1, z2.,.zn yang lebih kecil atau sama dengan zi

dengan rumus:

$S\left(z_{l}\right)=\frac{\text { banyaknya } z_{1}, z_{2} \ldots \ldots \ldots, z_{n} \text { yang } \leq z_{i}}{n}$

4) Menghitung selisih $F\left(z_{i}\right)-S\left(z_{i}\right)$ kemudian tentukan harga muttaknya.

5) Ambil harga paling besar diantara harga-harga muttak selisih itu, namakan

Lo. Dengan persamaan $L_{0}=$ maks $\left|F\left(z_{i}\right)-S\left(z_{i}\right)\right|$

Bandingkan harga $\mathrm{L}_{0}$ dengan nilai kritis $\mathrm{L}$ yang ada dalam tabel pada taraf nyata yang dipilih. $H_{0}$ diterima jika $L_{0} \leq L_{\text {idbece, dimana }} H_{0}$ mengatakan bahwa sampel berasal dari populasi yang berdistribusi normal.

b. Uji homogenitas variansi

Uji homogenitas variansi bertujuan untuk mengetahui apakah variansi kelompok sampel sama atau berbeda. Hipotesis statistik yang digunakan adalah:

$$
\text { Ho: } \sigma_{1}^{2}=\sigma_{2}^{2}
$$

$H_{l}: \sigma_{l}^{2} \neq \sigma_{2}^{2}$

\section{Dengan:}

$$
\sigma_{l}^{2}=\text { variansi kelompok eksperimen }
$$

$$
\sigma_{2}^{2}=\text { variansi kelompok kontrol }
$$

Untuk menguji hipotesis tersebut digunakan rumus statistik uji $\mathrm{F}$ sebagai berikut:

Jika $\mathrm{F}_{\text {hitung }}<\mathrm{F}_{\text {tabel }}$ maka $\mathrm{H}_{0}$ diterima yang berarti tidak ada perbedaan variansi antara kedua kelompok sampel. Jika demikian $\mathrm{H}_{0}$ ditolak dan $\mathrm{H}_{1}$ diterima. Berarti terdapat perbedaan variansi yang signifikan diantara kedua kelompok sampel.

\section{Uji Hipotesis}

Uji hipotesis dilakukan setelah dilakukan uji normalitas dan uji homogenitas terhadap kelas sampel. Untuk sebaran data tidak berdistribusi normal maka untuk menguji kesamaan dua rata-rata digunakan statistik uji nonparametrik yaitu U Mann Whitney (statistik U). Rumus statistik uji yang digunakan Siegel (1985:150) adalah sebagai berikut:

$$
\begin{aligned}
& U=n_{1} n_{2}+\frac{n_{1}\left(n_{1}+1\right)}{2}-R_{1} \\
& \text { Dimana: } \\
& U \quad \text { :Statistik uji Mann Whitney } \\
& n_{1, n_{2}} \text { : Ukuran sampel pada kelompok 1 dan kelompok 2 } \\
& R_{1} \quad \text { : Jumlah ranking yang diberikan pada kelompok yang ukuran } \\
& \quad \text { sampelnya } n_{1}
\end{aligned}
$$

Untuk sampel berukuran besar (n > 20), Siegel (1985:154) menyarankan untuk menggunakan pendekatan ke distribusi normal dengan bentuk statistik sebagai berikut: 


$$
z=\frac{U-\frac{n_{1} n_{2}}{2}}{\sqrt{\frac{n_{1} n_{2}\left(n_{1}+n_{2}+1\right)}{12}}}
$$

Dimana,

$\mathrm{z}$ : statistic uji $\mathrm{z}$ yang berdistribusi normal $\mathrm{N}(0,1)$

\section{HASIL DAN PEMBAHASAN}

A. Deskripsi Data

Data berikut diperoleh dari hasil tes akhir kemampuan komunikasi matematik pada kelas eksperimen dan kelas kontrol.

Tabel 13. Hasil Tes Kemampuan Komunikasi Matematik

\begin{tabular}{|c|c|c|c|c|c|c|}
\hline Kelas & $\begin{array}{c}\text { Nilai } \\
\text { Maksimal }\end{array}$ & $\mathbf{N}$ & Xmaks & Xmin & $\bar{x}$ & S \\
\hline Eksperimen & 40 & 35 & 40 & 7 & 25,33 & 9,26 \\
\hline Kontrol & 40 & 34 & 40 & 0 & 16,67 & 9,60 \\
\hline
\end{tabular}

Pada Tabel 13 tersebut, diperoleh rata-rata tes kemampuan komunikasi matematik kelas eksperimen lebih tinggi dari rata-rata tes kemampuan komunikasi matematik kelas kontrol. Skor tertinggi dan terendah pada kelas eksperimen lebih tinggi dari kelas kontrol. Hal ini menunjukkan bahwa kemampuan komunikasi matematik mahasiswa kelas eksperimen lebih baik dari kemampuan komunikasi matematik mahasiswa kelas kontrol.

\section{B. Pembahasan}

Berdasarkan hasil analisis data, model pembelajaran kooperatif tipe STAD memiliki potensi yang cukup baik untuk meningkatkan kemampuan komunikasi matematik mahasiswa. Hal ini dapat dilihat dari hasil analisis terhadap kesamaan rata-rata nilai tes akhir antara kelas eksperimen yang menggunakan model pembelajaran kooperatif tipe STAD dan kelas kontrol yang menggunakan metode konvensional, ternyata terdapat perbedaan. Dalam hal ini kelas eksperimen memberikan hasil yang baik dibandingkan dengan kelas kontrol.

Hal ini diduga karena dalam perkuliahan dengan model pembelajaran kooperatif tipe STAD mahasiswa berani menyampaikan ide/gagasan kepada teman sekelompok dalam menjawab soal-soal yang ada pada LKM. Selain itu model pembelajaran kooperatif tipe STAD ini terjadi komunikasi secara berpasangan. Kemudian saling mencocokkan jawaban dengan teman kelompok. Jika ada anggota kelompok yang belum memahami maka kelompok bertanggung jawab untuk menjelaskannya.

Dalam proses perkuliahan berlangsung selama penelitian, mahasiswa mulai terbiasa untuk menyampaikan ide atau gagasannya sehingga mereka tidak kesulitan dalam menulis dan mengkomunikasikan jawaban dari soal yang diberikan. Kondisi ini berdampak positif terhadap hasil belajar mahasiswa pada aspek komunikasi seperti yang diberikan pada tes akhir.

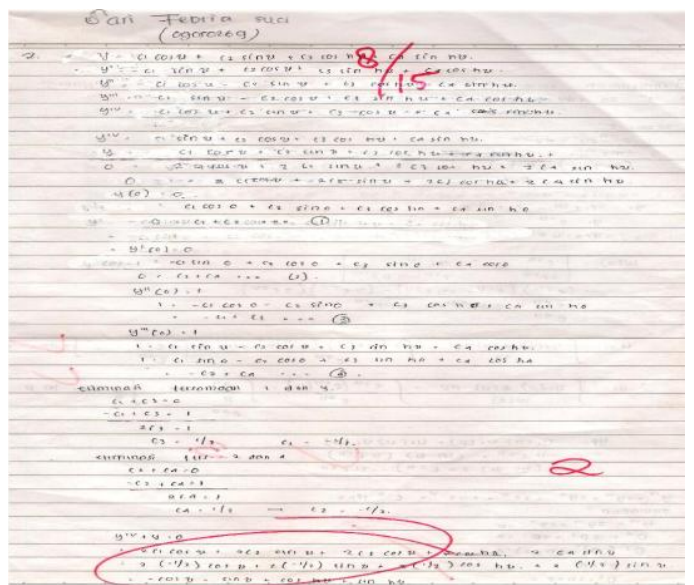

Gambar 1. Jawaban tes akhir pada persamaan diferensial homogen orde-n. 
Berdasarkan Gambar 16 di atas terlihat bahwa mahasiswa sudah mampu menyajikan ide matematika dalam bentuk aljabar dengan benar dan tepat. Dari persoalan yang diberikan, mahasiswa sudah mampu membuktikan $\mathrm{y}=\mathrm{c} 1 \cos \mathrm{x}+\mathrm{c} 2 \sin \mathrm{x}+\mathrm{c} 3 \cosh \mathrm{x}+$ $\mathrm{c} 4$ sinh $\mathrm{x}$ adalah solusi umum dari

persamaan diferensial yIV $+\mathrm{y}=0$. Penyelsaian soal yang dibuat mahasiswa

untuk membuktikan persamaan diferensial homogen dengan memisalkan $\mathrm{y}=\mathrm{emx}$, dan menurunkan fungsi $\mathrm{y}$ sebanyak orde. Hal ini dapat kita simpulkan bahwa mahasiswa sudah mampu menyajikan ide matematika dalam bentuk aljabar dan model matematik

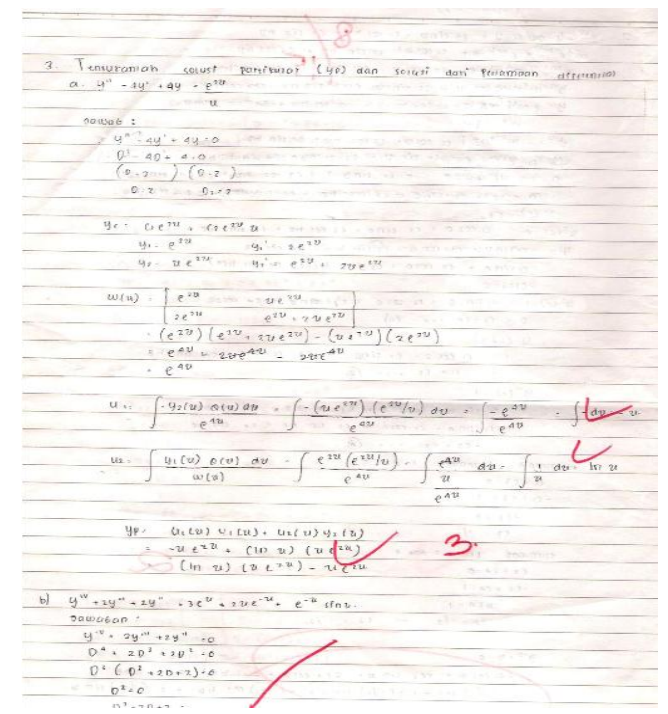

\section{Gambar 2. Jawaban tes akhir persamaan diferensial tak homogen orde-n}

Pada persoalan di atas, mahasiswa sudah mampu menggunakan struktur /pola untuk menyajikan ide matematika dengan benar dan tepat. Dapat dilihat dari jawaban mahasiswa untuk menyelesaiak fungsi partikur (yp) mahasiswa menggunakan struktur/pola variasi parameter. Hal ini dapat disimpulkan bahwa mahasiswa sudah dapat menggunakan struktur/pola penyelesaian dengan benar dan tepat.

Berdasarkan uraian di atas bahwa kemampuan komunikasi matematik mahasiswa pada indikator menyajikan ide matematika dalam bentuk aljabar, dan menggunakan struktur/pola dalam menyelesaikan persoalan matematika mengalami peningkatan yang signifikan. Hal ini disebabkan karena menggunakan model pembelajaran kooperatif tipe STAD dapat menfasilitasi peningkatan aktifitas mahasiswa dalam proses perkuliahan, dan mahasiswa menjadi aktif dalam proses diskusi kelompok.

\section{KESIMPULAN}

Berdasarkan analisis data yang telah dikemukakan maka dapat ditarik kesimpulan kemampuan komunikasi matematik mahasiswa yang mengikuti perkuliahan dengan model pembelajaran kooperatif tipe STAD lebih baik dari kemampuan komunikasi matematik mahasiswa yang mengikuti perkuliahan dengan konvensional.

\section{DAFTAR PUSTAKA}

Dahar, R. W. 1996. Teori-teori Belajar. Jakarta: Erlangga.

John A. 2008. Matematika Sekolah Dasar dan Menengah. Jakarta: Erlangga. Kurniawan. 2006. Siap Juara Olimpiade matematika SMP. Jakarta: Erlangga. Lisnawati. 1993. Metode Mengajar Matematika 1. Jakarta: Rineka Cipta.

Lie Anita 2002. Cooperative Learning, Mempraktikan Cooperative Learning di

Ruang-Ruang Kelas. Jakarta : PT. Gramedia Widiasarana Indonesia. 
Siegel, Sidney. 1997. Statistik NonParametrik untuk ilmu-ilmu sosial. Gramedia Pustaka Utama: Jakarta.

Sudjana.2002. Metoda Statistik. Bandung: Tarsito

Muslim Ibrahim. 2000. Pembelajaran Kooperatif .Surabaya: UNESA

Made Wena . 2009. Strategi Pembelajaran Inovatif Kontemporer. Jakarta: Bumi Aksara 